\title{
Patterns of Urban Heat-Wave Deaths and Implications for Prevention: Data from New York and St. Lovis During July, 1966
}

\author{
Stanley H. Schuman \\ Department of Epidemiology, School of Public Health, University of Michigan, \\ Ann Arbor, Michigan 48104
}

Received July 21, 1971

\begin{abstract}
Patterns of urban heat wave deaths in New York and St. Louis during July 1966 indicate not only the impact of environmental stress on heat-susceptible segments of the population but provide clues to the possible prevention of such deaths. While mortality from all causes increased by $36 \%$ in New York and by $56 \%$ in St. Louis certain subgroups were at substantially higher risk (persons over age 65; censustract residents with low income, crowding, or poor housing; those with hypertensive, arteriosclerotic, cardiovascular, or other circulatory disease, diabetes, or chronic respiratory disease). The oppressiveness of heat waves in cities is emphasized by increased rates of homicide and by clashes with police in the streets. On the brighter side, pediatric deaths were controlled during heat episodes in both cities, suggesting that medical, social, and environmental measures can intervene.

Unless the general approach to urban heat waves becomes prospective rather than retrospective, one can anticipate episodes of excess mortality during the summers of the 1970's with a human cost of about 136 excess deaths per million per week of heat stress.
\end{abstract}

\section{INTRODUCTION}

The summer of 1966 proved that heat waves (episodes of sustained high temperatures with or without high humidity) in U. S. cities are not a thing of the past, but a recurrent meteorological fact. That significant numbers of persons died during the heat wave in many U. S. cities indicates our failure to develop effective preventive measures for some heat-susceptible segments of our urban populations, and our failure to anticipate the consequences of heat stress in making our cities more livable and more healthful.

\section{METHOD OF EXCESS MORTALITY}

The method of excess mortality was developed by epidemiologists during the twenties to assess the impact of epidemics of influenza on populations and to derive ongoing expected curves of mortality which would give the health officer a baseline on which to plot weekly reported deaths (Serfling, 1963). The resulting curve of expected and observed deaths with an estimated tolerance zone for random fluctuation is illustrated for New York for the period April 1966-April 1967 in Fig. 1. Here we see expected weekly death rates plotted as a 5-year, 5-week moving mean with a $95 \%$ confidence zone (Weiner, 1968). Superimposed on the expected baseline (which has a summer depression and a winter eleva-

(C) 1972 by Academic Press, Inc. 


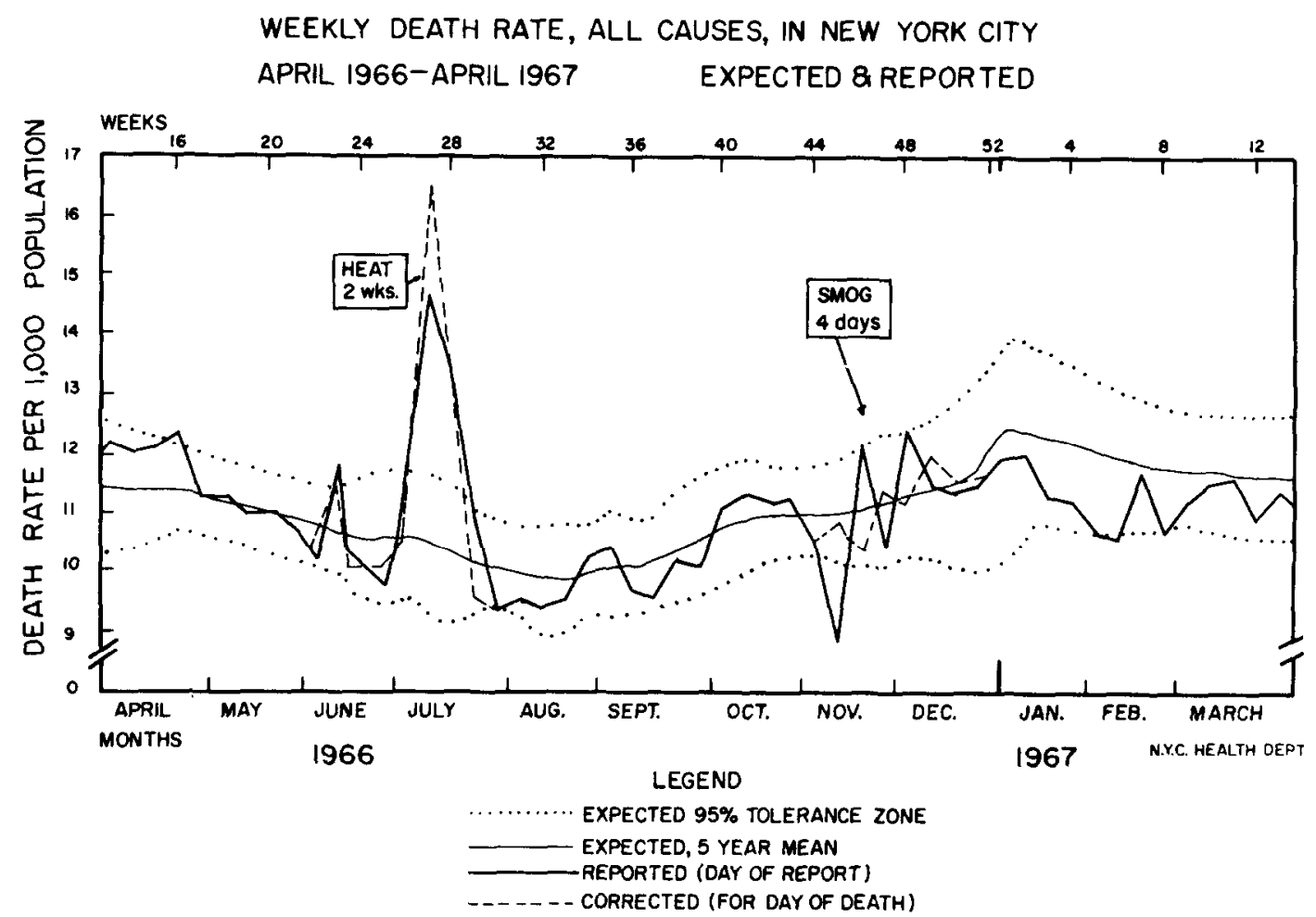

Fig. 1. Fluctuations in death rate in New York associated with episodes of heat (July 2-15) and smog (November 23-26) in 1966, illustrating the method of excess mortality. (Source of data: New York City Health Department.)

tion) are the weekly death rates for the current year, plotted as they are reported by day of report (heavy solid line) and replotted as the rate is corrected for actual day of death (interrupted line). Thus, in New York during one 12-month period there were four periods when the death rate seemed to exceed expectation: mid-April, early June, July, and November of 1966. The largest rise was accompanied by 2 weeks of excessive heat described by the U. S. Weather Bureau as "the result of a merger of three extraordinary high pressure systems that cover the central part of the nation, the Eastern Pacific and the Central Atlantic areas-a coincidence that amounts to a meteorological conspiracy to maintain unrelenting hot weather here. . .."1 Note that the peak of mortality is adjusted from about 15 to about 17 per 1000 population after the health department's statisticians corrected for day of death. The small April rise and June rise are brief, not sustained, and not easily explained. The November curve illustrates a well-known episode of 4 days of air pollution which occurred during the Thanksgiving holiday in New York. Although a rise in deaths was widely feared during the hectic days of the episode and although morbidity for chronic respiratory disease cases was reported, the corrected curve of weekly deaths by day

'New York Times, July 14, 1966, Section C-p. 39, "Relentless heat is almost a plot"; "Record hot spell reaches 101 here." 
of death (interrupted line) is well within the tolerance zone of chance expectation. This figure confirms the fact that heat episodes (like epidemic influenza) exert short-term, intense effects on mortality curves which most air pollution episodes do not.

\section{INTERURBAN COMPARISON OF HEAT-WAVE DEATHS}

Since Mary Gover's classic article on excess deaths in major U. S. cities during the thirties, there have been few reports comparing the impact of similar episodes in different urban settings (Gover, 1938). Similarities in patterns of deaths should offer some sense of replication and consistency; differences in the patterns should provoke searching questions.

Thus, from a single summer, in 1966 , which contained meteorologically similar heat episodes over a wide region, including cities of various sizes, it should be possible to learn more of the effects or lack of effects on urban populations. For simple quantitative comparisons such as numbers of excess deaths by age and by standard cause of death, the computations can be done retrospectively. As a minimum, such interurban comparisons should provide a means of grouping cities by severity of heat-associated mortality. For more complex analysis of heat wave effects one must focus on two or more cities in greater detail with proportionately greater effort.

\section{DEFINING A HEAT WAVE}

Defining a "heat wave" requires that some description and interrelation be made between the meteorological features and the mortality features of the episode. The more precise the definition of the heat episode is in terms of days of record heat, or of comfort-index days above a certain level, or of rises of mortality above a certain percentage, the more consistent is the methodology. On the other hand, we are only on the threshold of measurement in the sense that we do not know as yet how many times in several recent summers has a given city experienced heat episodes without a concomitant rise in mortality; only the noteworthy episodes are recorded or studied. From the viewpoint of prevention, the well-documented "escape" of an urban population from heat-wave conditions should be of equal interest to the "failure" of such a population to cope with heat stress. ${ }^{2}$ At the present level of surveillance of heat-related deaths in U. S. cities, there is little risk of overreporting; only occasionally does the National Center for Disease Control note the rise in mortality in early or late summer which affects groups of reporting cities which the epidemiologists are following primarily for signs of ep:demic influenza. Given that we have a relatively small sample of heat episodes in large cities for study, what new information can be gained that might be of use in considering recommendations for prevention?

In Table I data are summarized from an in-depth study of mortality rates before and during heat waves which gripped New York and St. Louis during July of 1966. The definition of the heat-episode period is arbitrarily selected to in-

"Personal communication: Dr. Thomas Downs, University of Texas School of Public Health, Houston, Texas, April, 1971. 
TABLE I

Comparison of Patterns of Heat-Wave Mortality in New York and St. Louis JuLY, 1966

\begin{tabular}{lcc}
\hline \multicolumn{1}{c}{ Characteristic } & New York & St. Louis \\
\hline $\begin{array}{l}\text { Population at risk, approximately } \\
\text { Duration of heat wave }\end{array}$ & 7.8 million & 728,000 \\
No. days over $90^{\circ} \mathrm{F}$ & 14 days & 28 days \\
Mortality & 12 & 24 \\
Excess deaths-estimated number" & 1181 & 618 \\
$\quad$ All ages-proportion rise & $36.3 \%$ & $55.8 \%$ \\
65+ years-proportion rise & $52.6 \%$ & $81.1 \%$ \\
"Rate" per million per week & 75.7 & 197.1 \\
Race & $39 \%$ & $41 \%$ \\
$\quad$ White & $20 \%$ & $119 \%$ \\
$\quad$ Nonwhite & $25.3 \%$ & $28.0 \%$ \\
Sex & $50.4 \%$ & $57.5 \%$ \\
$\quad$ Male & WF $56.2 \%$ & $\mathrm{NWF} 140.1 \%$ \\
$\quad$ I emale & $10 \%$ to $140 \%$ & $\mathrm{NWM} 88.6 \%$ \\
Race-sex group at highest risk & & $-18 \%$ \\
Range of excess deaths by resi- & & $260 \%$ \\
$\quad$ dence (census tract) & & \\
\hline
\end{tabular}

a Applying the method of excess mortality to an arbitrary control period (see text): For New York-2 weeks of "average" mortality during May 7-20, 1966; for St. Louis-4 weeks of mortality during July of $1965(7 / 2-7 / 29)$.

${ }^{b} \mathrm{WF}=$ white female, $\mathrm{NWF}=$ nonwhite female, $\mathrm{NWM}=$ nonwhite male.

clude 14 days in New York (July 2-15) and 4 weeks in St. Louis (July 2-29); similarly the choice of a control or comparison period varies. A reasonable choice for New York might have been a 2-week period in June preceding the period in July, such as June 2-15; but we have already noted in Fig. 1 that an abnormal rise in mortality occurred in mid-June for unknown reasons; therefore, a preceding period in May when mortality appeared more "usual" was the logical choice.

The major finding in Table I is that approximately 1181 persons in New York and 618 persons in St. Louis died during the heat episode who would have lived beyond the summer of 1966. One may ask, how many of these deaths may be directly attributed to heat? In St. Louis some 130 of the deaths were assigned to the international category E931 (death due to excessive heat and insolation) but in New York only a handful of deaths were so coded, preference being assigned in New York to underlying circulatory and degencrative cenditions. If one accepts the usefulness of the method of excess mortality (as influenza epidemiologists have found over the years) one can overlook differing customs of health departments and practicing physicians in coding deaths and concentrate on the distinct patterns of mortality in the available data.

The impact of the heat wave was greater on the city of St. Louis than New York because deaths were up 55.8\% compared to $36.3 \%$. The age group over 65 years was hardest hit by the heat stress, $52.6 \%$ rise over expected in New York 
and $81.1 \%$ in St. Louis. ${ }^{3}$ The fact that the cities have different populations at risk and had heat stress of different duration (16 days of maximum temperatures over $90^{\circ} \mathrm{F}$ in New York compared to 24 such days in St. Louis ) may be adjusted by expressing the deaths as a rate per million population per week. The rate for St. Louis clearly $\epsilon$ iceeds New York, 197.1 compared to 75.7. The combined deaths for the two cities gives a rate of about 136 excess deaths per million per week, or about 19-20 excess deaths per day of a severe urban heat wave. The other features of Table I summarize the data from analysis by sex and race and residence, and indicite clearly that white women were the highest risk group in New York (56.2\% rise compared to $36.3 \%$ for all persons), that nonwhite women and nonwhite men were higher-risk groups in St. Louis (140.1\% and $88.6 \%$ rise compared to $55.8 \%, \mathrm{r}$ all persons), and that place of residence of the deceased varied enormously trom low areas of 10 to $-18 \%$ excess mortality to high areas of +140 to $+260 \%$ excess mortality. What are the reasons for such interurban and intraurban variations in deaths precipitated by urban heat stress? Assuming that differences of these dimensions in such large urban populations are unlikely to occur by chance, one must consider the critical variables in heat-wave survival (based on facts derived from years of clinical, military, and industrial research): duration and severity of heat load; physiologic reserves of the host; environmental or medical methods of arresting the progression of heat illness (Burch and DePasquale, 1962; Leithead and Lind, 1964; Minard et al., 1957; Coburn and Reba. 1966; Lee and Henschel, 1966; Schuman, 1962).

\section{VARIATIONS IN HEAT WAVE MORTALITY BY AGE AND BY CAUSE OF DEATH IN NEW YORK}

Clues to the failure to survive the challenge of a heat wave are evident from the data summarized in Table II, and in Figs. 2 and 3. The size of the New York population at risk ( 7.8 million residents) lends confidence to one's analysis of deaths by subgroups. Thus, in Table II one is reminded that, whereas all causes of death were up by $36.3 \%$ over the May control period, only 6 of 16 major causes of death were elevated above expectancy. Arteriosclerotic heart disease accounted for 490 of the 1181 excess deaths and is illustratd in the curve for persons aged 80 years or more in Fig. 2, and in the curve for arteriosclerotic heart disease in Fig. 3. The "time lag" of a day or two before the rise in deaths occurs seen in Fig. 2 is most evident for persons aged 80 or more, but is more delayed for persons aged $45-€ 4$ years of age. The greater delay and lesser height of the curve for middle-aged persons suggest the greater resilience to heat challenge for most persons agec 45-64 years; those who succumb at younger ages would suggest a group of premature, possibly preventable deaths.

\footnotetext{
"For purposes of comparison it should be noted that during the 2-week period ending July 16, 1966 deaths from all causes increased 17.4\% among 21 reporting cities in five East North Central states (Ohio, Illinois, Indiana, Michigan, Wisconsin) compared to the similar 2-week period of 1965. Deaths for persons aged 65 or older increased by $22.5 \%$ in the same region. These data are calculated from Morbidity and Mortality Weekly Report, vol. 15, 1966, CDC-PHS-HEW, Atlanta, Georgia 30333.
} 
TABLE II

Major Causes of Excess Deaths in New York, July 2-15, 1966

\begin{tabular}{lrcrc}
\hline Cause of death & $\begin{array}{c}\text { Heat weeks } \\
\text { (observed) }\end{array}$ & $\begin{array}{c}\text { Control weeks } \\
\text { (expected) }\end{array}$ & $\begin{array}{c}\text { Excess in heat } \\
\text { wave }\end{array}$ & $\begin{array}{c}\text { Excess as \% of } \\
\text { expected }\end{array}$ \\
\hline All causes & 4431 & 3250 & 1181 & 36.3 \\
Homicide & 31 & 13 & 18 & 138.5 \\
Diabetes & 115 & 53 & 62 & 117.0 \\
Miscellaneous ${ }^{2}$ & 215 & 115 & 100 & 87.0 \\
Respiratory & 350 & 190 & 160 & 84.2 \\
Hypertension & 150 & 99 & 51 & 51.5 \\
ASHD & 1691 & 1201 & 490 & 40.8 \\
Genitourinary & 68 & 50 & 18 & 36.0 \\
Accidents & 142 & 106 & 36 & 34.0 \\
CVA & 355 & 279 & 76 & 27.2 \\
Cirrhosis & 127 & 105 & 22 & 21.0 \\
Digestive & 82 & 68 & 14 & 20.6 \\
Cancer & 770 & 657 & 127 & 19.3 \\
Other heart dis. & 199 & 169 & 30 & 17.8 \\
Infection & 22 & 19 & 3 & 15.8 \\
Infancy & 91 & 88 & 13 & 14.8 \\
Suicide & 23 & 38 & -15 & -39.5 \\
\hline
\end{tabular}

${ }^{a}$ Miscellaneous includes all other major causes of death: hematologic disorders; postoperative complications; endocrine diseases (nondiabetic); neurologic disorders; senility; ill-defined conditions.

The method of excess mortality demonstrates its usefulness in showing that while accidental deaths (including motor vehicle fatalities over the July 4th weekend) were above a comparison period in May by $34.0 \%$ this excess was not unusual compared to all causes being up 36.3\%. However, if we consider two other forms of violent death, homicide and suicide, a striking pattern of reversal appears in Table II and Fig. 3. After a "lag period" of about 1 week, the homicide rate for New York rises sharply while the suicide rate falls below the expected daily average rate. It would appear that the cumulative effects of unremitting heat can raise one's threshold for suicide but lower one's threshold for murder. Perhaps the anecdote recorded during the 10-day heat wave of August 1896 in New York ( 3000 persons and 2000 horses dying) is relevant at this point: “. . . on the corner of Bleecher and MacDougal streets, police were hurriedly summoned to stop a knife fight which erupted when one man jokingly asked another if the weather was hot enough for him" (Greenberg and Field, 1965).

The effects of oppressive heat on human aggressive behavior are perhaps so well known that further documentation is repetitious. Unfortunately, massive discomfort and disease does not make the news unless it erupts in violence. It is interesting to note that violence on the streets did not erupt in New York with the temperatures in the nineties while it did occur for two nights, July 13-14, 1966, in Chicago's West Side with the temperature only in the eighties. The set and the setting are obviously important where humans, emotions, heat, and crowding are involved. The reporter of the near race riot with scores of police and demonstrators injured from llying bricks, glass, and fire bombs, suggests a 


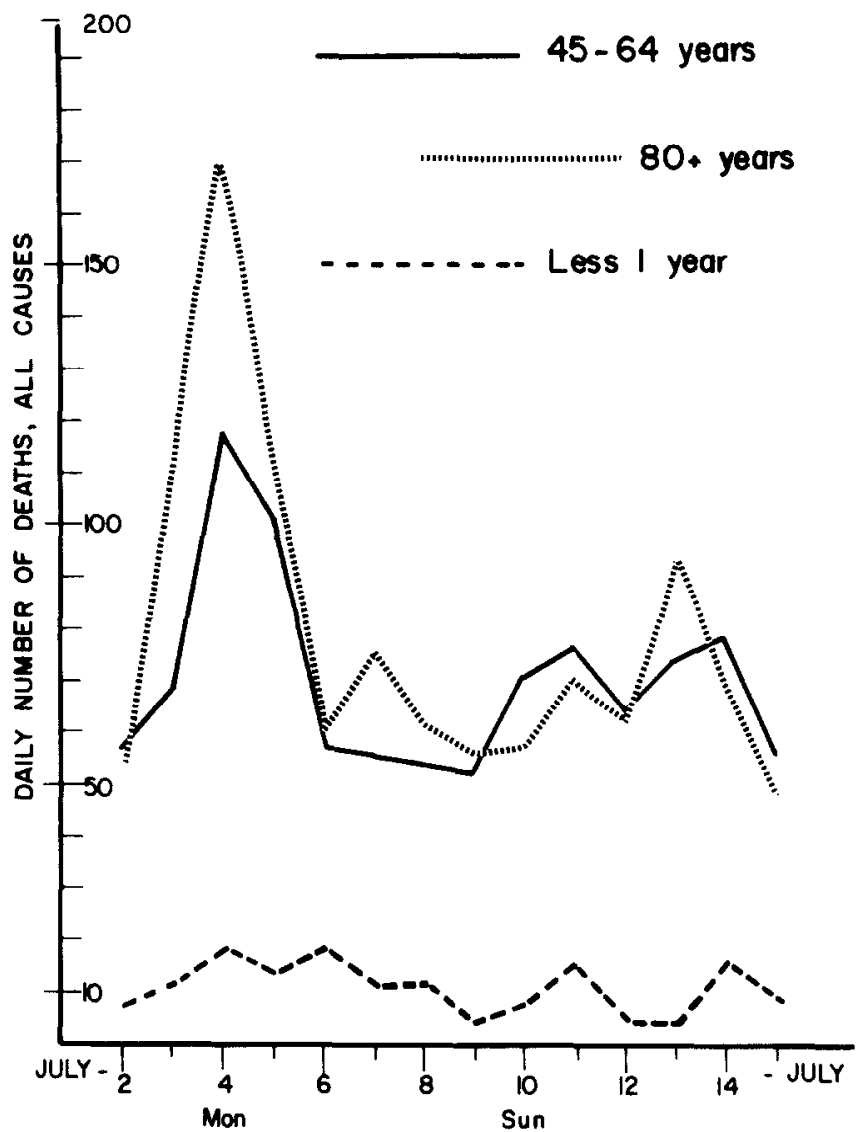

FIG. 2. Daily deaths, all causes, for selected age groups in New York, July 2-15, 1966.

provocative act: "For the second day in a row the police turned off a gushing fire hydrant along Roosevelt Road near the Loop, although it is a summer tradition in Chicago to cool off with gushing hydrants." 4

Among the causes of death listed for New York the category "respiratory including pneumonia and influenza" showed a rise of $84.2 \%$. This drew the attention of the epidemiologists at the National Communicable Disease Center who wondered about the 2 -week rise in this cause of death as the signal for a midsummer ( $?$ ) outbreak of influenza; strange events sometimes happen, but this possibility proved to be a false alarm. Another possible cause of a rise in deaths from respiratory disease might be the combined effects of stagnant warm air and polluted air in New York. During the episode, the New York Times reported, "The pollution index on Wednesday, (July 13) was 13 compared to the usual 6 or 7 for this time of year." The air-pollution levels did not approach the levels of concern that were attained later in New York in November, 1966 of over 20. The additive effects of air pollutants and heat on the cardiopulmonary systems of

\footnotetext{
"Associated Press to Ann Arbor News, July 14, 1966 "Fire bombs, shots fly in wild Chicago melee."
} 


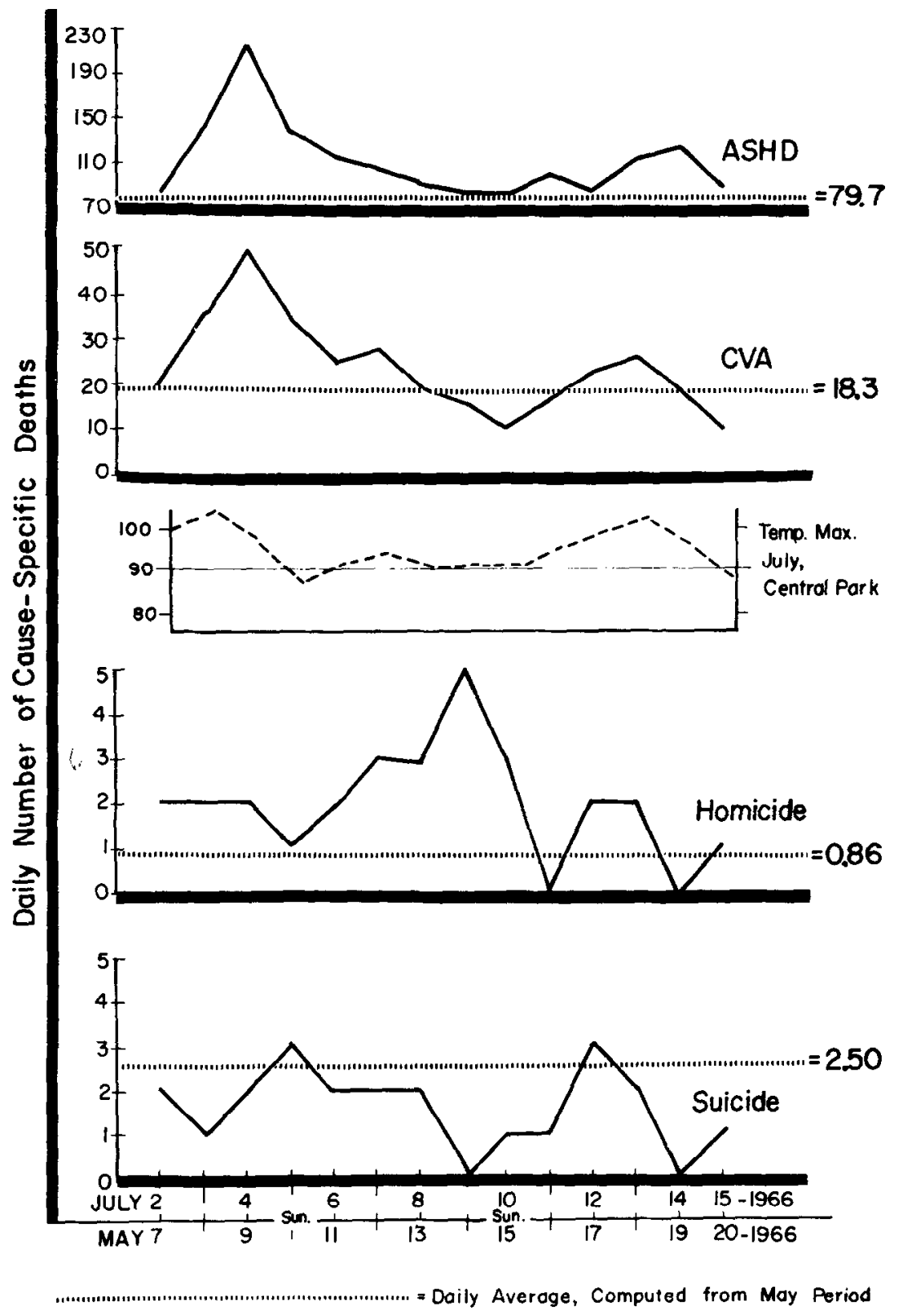

FIG. 3. Daily deaths, selected causes in New York, July 2-15, 1966.

handicapped persons should not be minimized but heat stress would seem to be the dominant factor during July of 1966 . A simpler explanation for the rise in respiratory deaths would be the assignment of deaths during the hot spell to the terminal event by many physicians (terminal pneumonia, following stroke, heart failure, chronic cardiopulmonary disease, etc.).

The $34.0 \%$ rise in cerebral vascular accidents (CVA) in Table II is not impres- 
sive but the timing of the sharp rise for the first week of the heat wave in Fig. 3 coincides with the sharp rise in arteriosclerotic heart disease. It seems that coding of deaths attributable to cerebral strokes in New York differs from coding in St. Louis (see Fig. 5) and tends to understate the problem documented in heat wave studies in Detroit, Los Angeles, and other cities (Schuman et al., 1964; Bridges and Helfand, 1968). It is reasonable to conclude that circulatory handicaps will predispose persons to die during heat episodes regardless of the diagnostic category chosen for certification of death.

Finally, it should be noted from Table II and Fig. 2 that the leading causes of death during infancy. (less than 1 year of age) are not elevated during the heat wave. Rclated catcgories, such as digcstivc disorders and infection (diarrhea, dysentery, dehydration), are not increased. These data illustrate the fact that pediatric deaths during urban heat waves are being effectively controlled; while geriatric deaths are not.

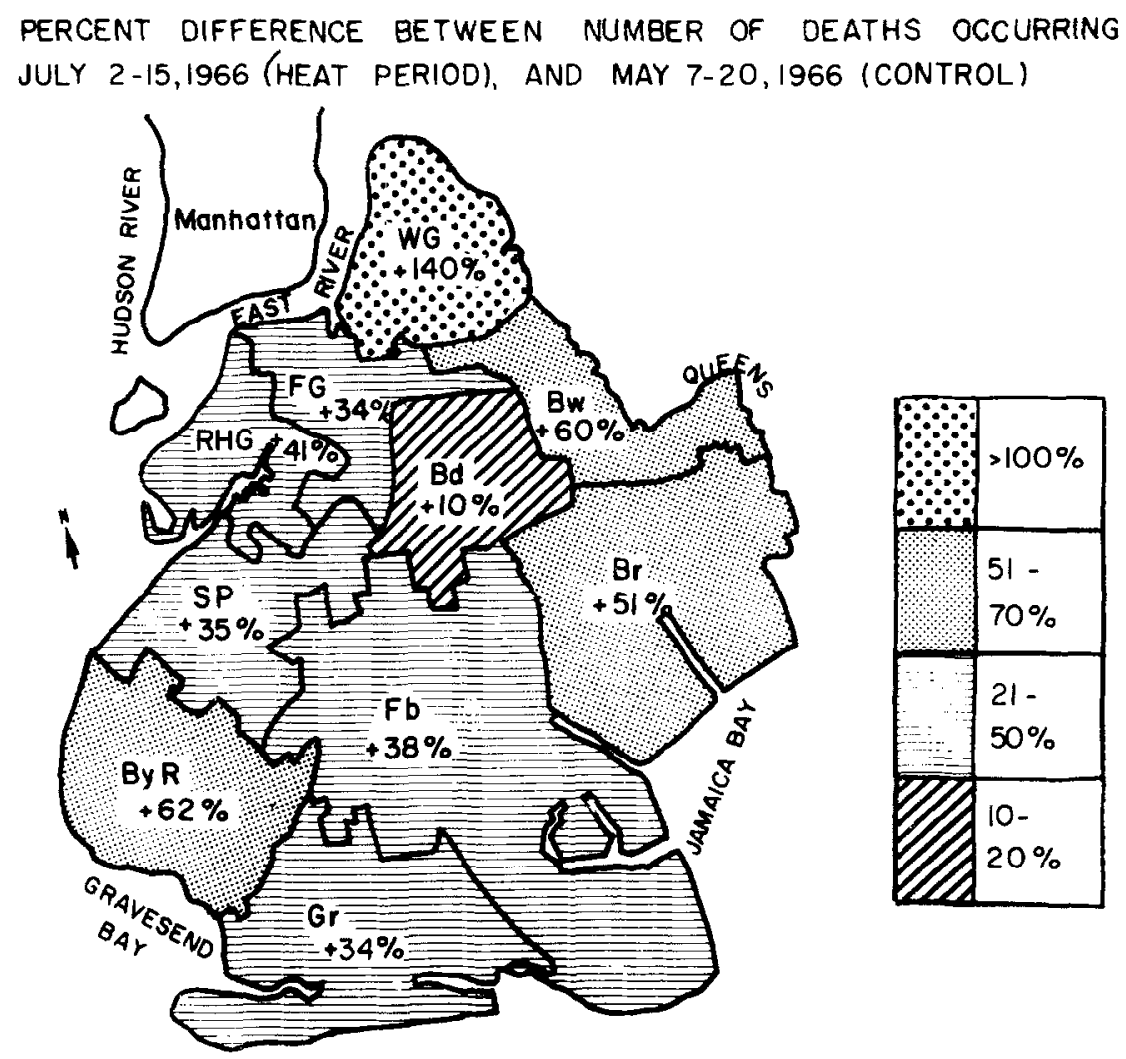

WG $=$ Williamsburg-Greenpoint, $F G=$ Fort Greene, RHG = Red Hook Gowanus, $B d=$ Bedford, Bw= Bushwick, $S P=$ Sunset Pork, $F b=$ Flatbush,

$\mathrm{Br}=$ Brownsville, ByR= Bay Ridge, $\mathrm{Gr}=$ Gravesend

Frc. 4. Distribution of heat-related deaths among the 10 health districts of Brorkjyn July 2-15, 1966. 


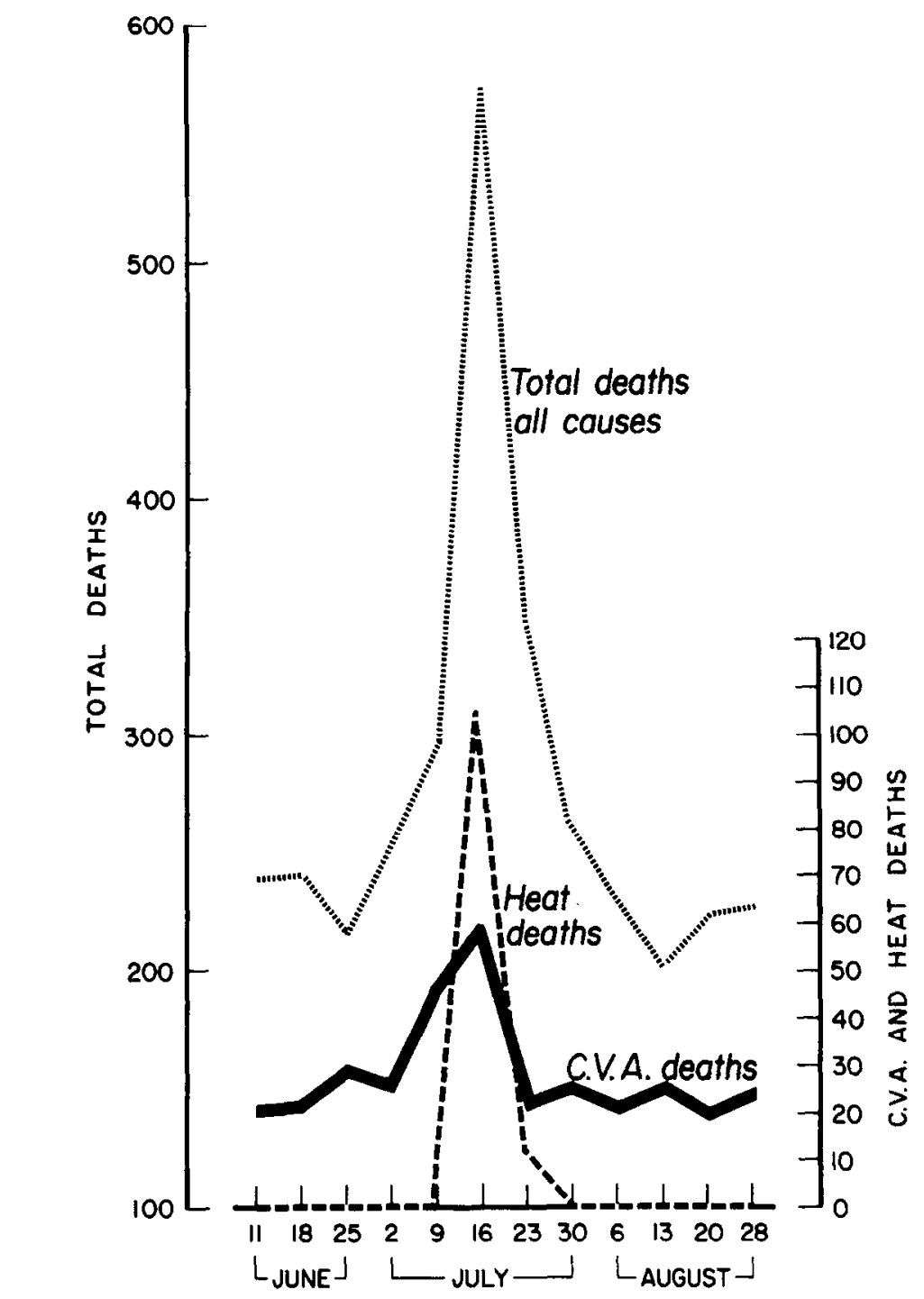

No. doys $90^{\circ}-99^{\circ}$
No. days $100^{\circ}+$

FIG. 5. Weekly temperatures and deaths (all causes and selected causes) in the City of St. Louis, July 1966.

\section{TIMING OF THE HEAT WAVE DEATHS IN ST. LOUIS}

Analysis of the heat-related deaths in St. Louis was carried out in similar fashion to that for the data for New York but not in as great detail (cause of death). Most attention was given to the timing of heat-related deaths and their place of residence.

In Fig. 5, the dcaths arc shown on a weckly scalc for June, July, and August in order to emphasize the surveillance possibilities available for earlier recogni- 
tion of impending urban heat-wave episodes. In addition to the meteorological forecasting that is available on a probability basis, attention to the weekly patterns of mortality in a city such as St. Louis during the summer months might actually forewarn the community (again on a probability basis) to take greater precautions.

The deaths can be plutled by day of death with more detailed temperature data but the cruder scale serves well enough to emphasize certain essential facts about the timing of heat deaths in St. Louis: (1) Actually 4 weeks in July were characterized by above-normal deaths for all causes; weeks ending July $9,16,23$, and $30 ;(2)$ deaths actually began to rise during the week ending July 2; (3) deaths attributed to cerebral strokes (CVA) began to rise quite sharply and proportionately more than deaths from all causes; (4) heat deaths as such were not coded in St. Louis until 2 weeks after the deaths from all causes began to rise (perhaps the televised daytime all-star baseball game on July 12th with athletes and scores of spectators collapsing focused attention on the heat); (5) the decline in deaths from all causcs was slowcr by 2 wecks than the decline in heat deaths, and (6) the decrements in deaths expected statistically in August to compensate for the rise in July do not become evidence in August for either all calnses or for CVA.

In retrospect, it would seem that if attention had been focused on deaths attributable to CVA (or deaths of persons over age $65+$ years) as highly susceptible segments of the population during an incipient heat wave, the health facilities and environmental agencies of the community could have been alerted. During the week ending July 2 , there were 25 death certificates coded for CVA, well within the 20-30 range of expectation, but by the week ending July 9 , there were 47 deaths coded as CVA. On July 5th there were 10 such deaths, followed by eight more CVA deaths on July 6th! Thus, 18 cerebral stroke deaths in 2 days could have aroused suspicion at least 6 days before the baseball game and before general public awareness of a heat wave.

In addition to the possible use of heat-susceptible deaths as a "sentinel" marker of heat-wave deaths, better environmental information should he available to an alert health-protection agency. Thus, the continued use of meteorological data from county-based Lambert Air Field for St. Louis weather is likely to continue a serious underestimate of the actual temperature conditions in the inner city where many of the heat-related deaths occurred. Similarly, the New York temperature readings are from Central Park not the tenements of Brooklyn.

\section{INTRAURBAN VARIATION OF HEAT DEATHS RAISES QUESTIONS}

Careful study of heat-related deaths within metropolitan areas by place of residence of the deceased is fraught with methodological difficulties. The findings from geographical analysis of heat deaths in St. Louis and Brooklyn are presented (Tables III and IV, Figs. 4 and 6 ) in order to raise the epidemiological questions which must be asked, before preventive measures can be evaluated.

Methodologically, one would likc to havc more accurate census estimates of population at risk for each census tract and demographic characteristics but 1966 was an intercensal period. Nevertheless, it is reasonable to assume that the dis- 
TABLE III

Demographic Characteristics of Selected Census Tracts ${ }^{a}$ In St. Louis, July, 1966

\begin{tabular}{|c|c|c|c|c|c|c|}
\hline \multirow[b]{2}{*}{ Demographic characteristics } & \multicolumn{3}{|c|}{ High-risk tracts ${ }^{b}$} & \multicolumn{2}{|c|}{ Low-risk tracts ${ }^{c}$} & \multirow{2}{*}{$\begin{array}{l}\text { City } \\
\text { of St. } \\
\text { Louis }\end{array}$} \\
\hline & Ldl & $\mathrm{MC}$ & Gfd & NW & Gdv & \\
\hline Population (thousands, est. 1965) & 23.7 & 15.9 & 58.6 & 28.8 & 18.7 & 728 \\
\hline \multicolumn{7}{|l|}{ Excess deaths } \\
\hline Number & 52 & 25 & 57 & -8 & -3 & 618 \\
\hline Percent & +260 & +179 & +110 & -18 & -10 & +55.8 \\
\hline Median age & 35.1 & 26.2 & 29.6 & 40.5 & 43.3 & 33.6 \\
\hline Race (\% nonwhite) & 38.9 & 52.8 & 97.9 & 11.1 & 0.0 & 35.8 \\
\hline Median family income & $\$ 3600$ & $\$ 3400$ & $\$ 3500$ & $\$ 6200$ & $\$ 6700$ & $\$ 5300$ \\
\hline Crowding (no. persons/room) & 0.70 & 0.83 & 0.72 & 0.55 & $<0.50$ & 0.64 \\
\hline
\end{tabular}

a Census data from 1960 .

${ }^{b}$ High-risk tracts are: $\mathrm{Ldl}=$ Lindell, $\mathrm{MC}=$ Mill Creek, Gfd $=$ Garfield .

${ }^{c}$ Low-risk tracts are: $\mathrm{NW}=$ Northwest, $\mathrm{Gdv}=$ Gardenville.

crepancy between poor housing districts and better housing districts in Brooklyn or in St. Louis in 1966 did not change too much from the discrepancy as measured in the census of 1960 .

When the St. Louis data were first plotted and analyzed (Table III and Fig. 6) geographically, the variation in excess death rates was striking. The rates ranged from $-10 \%$ and $-18 \%$ (in Northwest and Gardenville) to $+260 \%,+179 \%$, and $+110 \%$ (in Lindell, Mill Creek, and Garfield). Could such variation be due to chance? If not by chance, could the environmental stress differ greatly for an area such as Forest Park $(+94 \%)$ with large acreage of parkland compared to an area of concrete such as Mill Creek $(+179 \%)$ or Downtown $(+141 \%)$ ? As

TABLF IV

Demographic Characteristics of Shifetro Health Districts in Brooklyn, JULY $2-15,1966^{a}$

\begin{tabular}{|c|c|c|c|c|c|}
\hline \multirow[b]{2}{*}{ Demographic characteristics } & \multicolumn{3}{|c|}{ Health districts ${ }^{b}$} & \multirow[b]{2}{*}{ Brooklyn } & \multirow[b]{2}{*}{ NYC } \\
\hline & WG & Gr & $\mathrm{Bd}$ & & \\
\hline Population (thousands, 1964) & 187 & 307 & 281 & 2615 & 7840 \\
\hline \multicolumn{6}{|l|}{ Excess deaths } \\
\hline Number & 64 & 42 & 11 & 433 & 1181 \\
\hline Percent & 140 & 33 & 10 & 44.5 & 36.3 \\
\hline Age of residents ( $\% 65$ years and older) & 10.4 & 10.1 & 5.9 & 9.9 & 11.2 \\
\hline \multicolumn{6}{|l|}{ Income measures } \\
\hline Median family income & $\$ 5500$ & $\$ 6600$ & $\$ 4400$ & $\$ 5100$ & $\$ 5100$ \\
\hline Rent (gross median) & $\$ 59$ & $\$ 80$ & $\$ 69$ & $\$ 70$ & $\$ 73$ \\
\hline Poverty areas ${ }^{c}$ & $7 / 10$ & $2 / 13$ & $10 / 11$ & $55 / 115$ & - \\
\hline Infant mortality (1964) & 31.4 & 17.5 & 41.9 & 29.4 & 26.8 \\
\hline
\end{tabular}

a Census data from 1960.

${ }^{b}$ Health districts are: $\mathrm{WG}=$ Williamsburg-Greenpoin, $\mathrm{Gr}=$ Gravesend, $\mathrm{Bd}=$ Bedford.

c Number of census tracts classified as poverty areas based on three indices by Poverty Area Study Office of City Administrator May 1, 1966, New York City. 


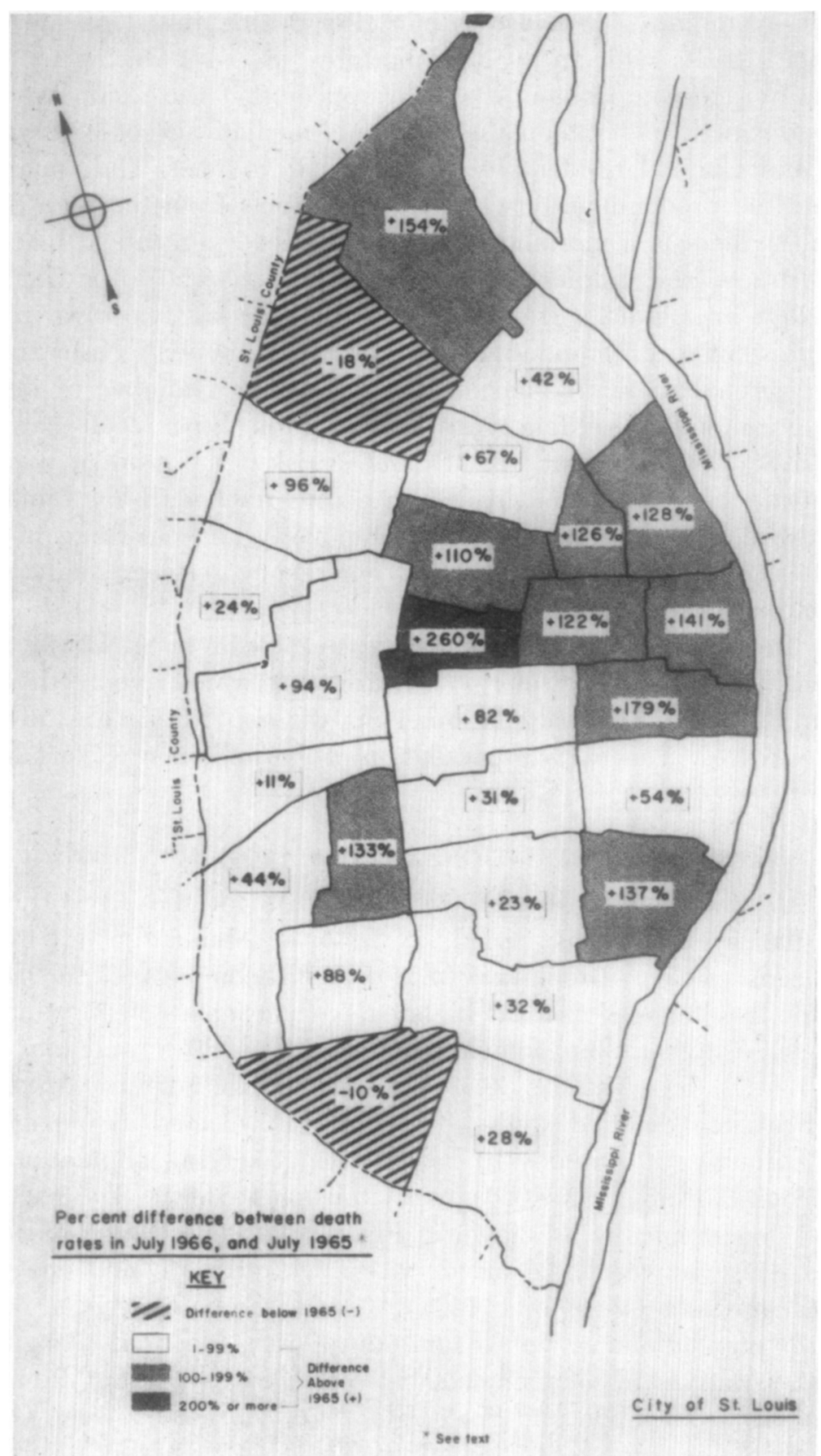

FIG. 6. Distribution of heat-related deaths among the 26 census tracts of St. Louis, July, 1966.

noted previously, the meteorological readings needed to answer such a question are not yet available although isothermal mapping of cities is a well-known technique. Could demographic and housing variables play a part in the variation? The data listed in Table III suggest a pattern, where three selected high-risk 
census tracts averaging $+183 \%$ excess mortality during July 1966 are compared to two low-risk tracts with an average mortality of $-14 \%$ during the month of record heat. By age composition, it would appear that the residents of low-risk tracts were distinctly older than the St. Louis median age of 33.6 years while Mill Creek and Garfield residents were somewhat younger. The racial comparisons separate the predominantly white low-risk tracts from the high-risk, mixed racial tracts. If there is a mortality gradient by race (percentage black) within the low-risk tracts, the gradient favors being black $(+110 \%$ for Garfield compared to $+260 \%$ for Lindell $)$. It seems logical that the last two rows in Table III are most consistent in differentiating high-risk from low-risk census tracts in St. Louis, namely, median family income and crowding (number of persons per room ). If we combine these data with those in Table I, we recall that on a citywide basis, a St. Louis resident was at greatest risk if the resident was over age 65 years, female, and black, and lived in a ccnsus tract with low family incomc and high crowding. Thus, the alleviation of poverty and crowding in the inner city as well as provision of medical and emergency services might save lives dramatically during urban heat waves.

Although the contrasts between tracts are so evident in St. Louis, one could become uneasy about comparisons of census tracts which averaged 28,000 and ranged from 11,000 to 58,000 population. Thus, the opportunity to study a similar heat episode in New York with a population of 7.8 million was considered most advantageous.

\section{INTRAURBAN VARIATIONS IN NEW YORK, JULY 1966}

Although the heat-related deaths were up 36.3\% for the city of New York (Table I) the five boroughs varied, as follows: Manhattan (20.0\%), Bronx (18.8\%), Queens (44.5\%), Brooklyn (44.5\%), and Richmond (37.9\%). It was already evident that females were at higher risk than male (50.4\% vs $25.3 \%)$ that white rates were higher than nonwhite rates (39\% vs $20 \%)$, and that white females were hardest hit ( $56.2 \%$ vs $36.3 \%)$; how would the pattern vary by area of residence? For such detailed study, Brooklyn was selected as one of the two higher risk boroughs; it contains 10 hcalth district serving populations ranging from Red Hook-Gowanus $(157,000)$ to Flatbush $(485,000)$. The excess deaths were plotted geographically as shown in Fig. 4 and again there appeared to be a striking contrast between one low district (Bedford 10\%) and one very high district (Williamsburg-Greenpoint 140\%). Could these differences be due to chance? With populations of this magnitude at risk, it would seem to be $1 \mathrm{~m}$ likely. Could variations in microclimate between various parts of Brooklyn during the heat wave be important? Such data would be hard to find. Other variables were available for study, shown in Table IV. Another health district (Gravesend) whose rate of $33 \%$ is somewhat below the Brooklyn average of $44.5 \%$ is included in the table for purposes of comparison. Here we see that the age factor is critical, that the Bedford population is distinctly younger than that of the other districts $(5.9 \%$ aged 65 or older compared to $10.4 \%$ or $10.1 \%$ ). Somehow despite its poverty (10/11 areas so designated in 1966) this younger population managed to survive the heat wave better than any of the other nine districts in 
Brooklyn. Were the high-risk groups of poor infants and children somehow protected during this period of heat stress? If so, the mothers and medical services of the area must deserve some credit. This is in contrast to the high annual infant mortality rate of Bedford (41.9) compared to Brooklyn (29.4). The differences between Williamsburg-Greenpoint and Bedford underscore the importance of age and income: the poor older residents died from heat stress at a greater rate than the poor young residents. Gravesend at the lower range of heat mortality $(34 \%)$ is characterized by an older population similar to Williamsburg-Greenpoint, but the level of income was distinctly superior for the Gravesend residents. Racial characteristics of the Brooklyn health districts were not investigated. The findings in Table I already suggested a white/nonwhite ratio of $2: 1 \quad(39 \%: 20 \%)$ for New York in contrast to St. Louis with a ratio of $1: 3(41 \%: 119 \%)$. If the race ratios were adjusted for income, housing, and age, would they be similar between the cities? Such analysis would require more detail than the data now permit, but offer a challenge for the next urban study of heat-wave mortality.

\section{DISCUSSION: IMPLICATIONS FOR PREVENTION}

The picture of urban heat-wave mortality in the past decade is not reassuring. Given two major cities, such as New York or St. Lowis, with a 2-week period of unremitting heat (not necessarily record-breaking), a sharp rise in deaths from all causes is likely to occur. In 1966, the human cost was about 76-197 lives per million residents per week of hot spell. This toll may not seem excessive, but the fact that the rate varied within each city by residential areas and by demographic characteristics suggests that the poor, the disadvantaged, the elderly, and those with circulatory handicaps bore the brunt of the environmental stress. Those with higher income, better medical care, fewer handicapping conditions, air conditioning, or access to the cooler suburbs experienced normal or subnormal death rates during the heat wave period.

On the encouraging side, it should be noted that pediatric deaths due to diarrhea, dehydration, and infections which were prevalent during the summers of the twenties and thirties in the U. S. were not increased during the heat waves in either major city in 1966. It would seem that the challenge of the clderly and the circulatory-handicapped residents of the city could be met with the same vigor, intelligence, and scientific knowledge which is working so well for the very young.5

The preventive approaches to adaptation to heat-wave stress must include

\footnotetext{
"The age-specific analysis of excess deaths in the age groups under 28 days, $1-11$ months, and 1-14 years for St. Louis shows the following pattern: -12 deaths, +14 deaths, and +7 deaths for July 1965 compared to July 1966. The numerical increase for the latter two age groups is small, but the percentage increase is notable. For New York, the increase over 2 weeks was +21 and +49 deaths for age groups less than 1 year and 1-14 years, numerically small but proportionately significantly increases. The cause-specific analysis for the latter age group shows the increase to be among miscellaneous causes, including metabolic disorders $(+23$ deaths $)$, accidents, including drowning $(+11$ deaths $)$, cancer $(+9$ deaths $)$, and respiratory ( +8 deaths). Thus, the traditional causes of infant and pediatric deaths during heat waves are notably absent-gastrointestinal disease (no excess deaths) and infectious clisease (no excess deaths).
} 
three disciplines: medical, social, and environmental. From an emergency point of view, medical care is primary but from a preventive or longer-term view, environmental change must be planned. During the immediate hectic days of an incipient heat wave, the emergency rooms and personnel are rapidly overwhelmed and a series of heroic but losing battles are fought. Even the medical skills and teamwork so hard earned during the heat wave are likely to be lost from disuse and personnel changes before the next heat wave occurs. During the less hectic days of planning for urban renewal, architects, engineers, and landscapers can provide a margin of safety for belcagucred rcsidents during heat waves-well-spaced parks and ponds; apartments and homes with cross-ventilation capabilities when the air conditioners break down or the power supply is rationed. The challenge for social change and improvement remains and is clearly indicated by these data to be equally needed by the races, by the crowded and poorly housed wherever they live, in the Midwest or the East. Finally, the morbidity, discomfort, irritations, and mental stress of heat waves should not be underestimated in the future as the quality of life comes to be of greater concern to the well-being of cities and city-dwellers.

\section{SUMMARY}

An unusual period of heat stress blanketed St. Louis, the Midwest, and New York in late June and mid-July of 1966 . Deaths from all causes increased by $24 \%$ in three Atlantic states, 17\% in five North Central States, 36\% in New York, and $56 \%$ in St. Louis. Subgroups of the population were hit harder (white females in New York 56\%, nonwhite females $140 \%$ in St. Louis). Residents of certain areas of the cities were almost unaffected by heat-wave mortality $(-18 \%,-10 \%)$ while in other areas deaths were up by 140 to $260 \%$. Poverty, crowding, poor housing, and age are critical factors. Diabetic deaths were up 117\%. ASHD and hypertension were increased by 41 to $52 \%$ in New York. Homicides were up remarkably while suicides were down during the hot spell. Sudden heat deaths (DOA's) and heat strokes were coded routinely in St. Louis but rarely by New York physicians. The timing of the deaths and the relation to meteorologic conditions makes such variations in nosology irrelevant when the classic method of excess mortality is applied to the data.

Not only do the cities fail to plan for the prevention of the adverse effects of heat stress on residents, but during the emergency conditions the medical facilities and environmental services are easily overwhelmed, the power shortages, lack of air conditioning, refrigeration, ice, relief areas, or emergency personnel become acute. Factories, labor and management, seem to demonstrate more concern for their workers than hospitals for patients, nursing homes for residents, or cities for their average dwellers.

Surveillance of incipient meteorologic conditions is feasible on a probability basis, and daily monitoring of city deaths, especially the sentinel CVA group of deaths (or persons aged 65 and older) could provide a week's warning before the full brunt of heat-wave deaths occur.

Unfortunately, the grim patterns of urban heat deaths in the decade of the sixties are so consistent between cities (New York, St. Louis, Los Angeles, De- 
troit, Madison-St. Clair) that it is predictable that heat-wave episodes will recur in the seventies, unless the problem gains wider attention. Is it possible that the infrequency of heat waves keeps them in the realm of the supernatural rather than the scientific area of our thinking? The possibilities for prevention of heatwave deaths are limited but they are within the range of our knowledge and skills.

\section{ACKNOWLEDGMENTS}

The assistance of James T. Oliver, Lester Z. Creley, and Louis Weiner as chief statisticians in the vital records departments of Detroit, St. Louis, and New York is gratefully acknowledged.

This study was supported by HEW-PHS-NIH-General Research Support Grant RR $05447-10$.

\section{REFERENCES}

Bridges, C. A., And Helfand, L. A. (1968). Mortality from heat during July 1966 in Illinois. Int. J. Biometeorol. 12, 51-70.

Burch, (r. E., ann DrPasquale, N. P. (1962). "Hot Climate, Man and His Heart." Thomas, Springfield, Illinois.

Cosunn, J. W., and Reba, R. C. (1966). Potassium depletion in heat stroke: a possible etiologic factor. Mil. Med. 131, 678-687.

Gover, M. (1938). Mortality during periods of excessive temperature. Publ. Health Rep. $53,1112-1143$.

Greenberg, L., Avd Field, F, (1965). The deadly heat wave of 1896, New York Magazine (June 20) N. Y. Herald Tribune, New York.

Lee, D. H. K., And Henscaer, A. (1966). Effects of physiological and clinical factors in response to heat. Ann. N. Y. Acad. Sci. 134, 743-749.

Leithead, C. S., And Lind, A. K. (1964). "Heat Stress and Heat Disorders." Davis, Philadelphia.

Minard, D., Belding, H. S., and Kingston, J. R. (1957). Prevention of heat casualties. J. Amer. Med. Ass. 165, 1813-1818.

Schuman, S. H. (1962). Host factors and environment in studies of human sweat. Ind. Med. Surg. 31, 443-449.

Schuman, S. H., Anderson, C. P., And Oliver, J. T. (1964). Epidemiology of successive heat waves in Michigan in 1962 and 1963. J. Amer. Med. Ass. 189, 733-738.

Serfling, R. E. (1963). Methods for current statistical analysis of excess pneumonia influenza deaths. Pub. Health Rep. 78, 494-506.

Weinen, L. (1968). New York City Department of Health's weekly statistics report. Pub. Health Reports 83, 377-382. 